\title{
Apresentação do artigo "A assimilação dos judeus” (1945), de Emílio Willems
}

\author{
Presentation to the article "The assimilation of Jews" (1945), \\ by Emilio Willems
}

\author{
Mário A. Eufrasio
}

Nesta última década tem-se visto a republicação de vários artigos de Emilio Willems e agora é a vez de “A Assimilação dos Judeus", que é oportuna por revelar algumas peculiares facetas desse autor. Publicado em 1945, quando ainda não se tinha uma ideia mais precisa da proporção a que chegara o genocídio dos judeus durante a II Guerra Mundial, nesses quase 75 anos o artigo não perdeu interesse e atualidade; alguns termos apresentaram mudanças ('miscigenação', 'intercasamentos', 'chassidismo' e outros), mas não seus significados.

A rejeição em tratar os judeus como uma raça ou como um povo, e sim como "grupos”, e a insistência em tratar a assimilação como um processo social ou sócio-psicológico são pontos altos da abordagem de Willems, que não abre mão de fazer uso de uma informação histórica preciosa para a caracterização e a diferenciação dos grupos judaicos e as condições e circunstâncias de sua assimilação.

Willems já foi apresentado neste periódico quando da publicação da tradução de "Mudança cultural entre imigrantes japoneses no Brasil, no Vale do Ribeira de São Paulo', (Apresentação da Tradução)”, em Plural, v. 19.1, 2012, pp. 135-138. Resumidamente: Emilio Willems (1905-1997), nasceu próximo de Colônia, no Oeste da Alemanha, numa família católica; estudou Sociologia e Etnologia em Berlim, de onde veio em 1931 para o Brasil, e morou em Santa Catarina, no Paraná e em São Paulo, até 1949, quando foi lecionar na Universidade Vanderbilt, em Nashville (no Tennessee), nos Estados Unidos, lá se aposentando em 1975. Aqui lecionou na Escola de Sociologia e Política e na Faculdade de Filosofia, Ciências e Letras da USP, tendo feito estudos sobre assimilação e aculturação de imigrantes e sendo um pioneiro nos estudos de comunidades e da "cultura caipira" entre nós.

Dificuldades de saúde impediram o professor Oracy Nogueira de levar a cabo um volume da Coleção "Grandes Cientistas Sociais" na década de 1980, por solicitação do Prof. Florestan Fernandes, e até agora ninguém se dispôs a retomar de

a Professor Doutor do Departamento de Sociologia da Faculdade de Filosofia, Letras e Ciências Humanas - Universidade de São Paulo. E-mail: eufrasio@usp.br. 
modo aprofundado e detalhado a análise da obra de Willems, pelo menos nas duas décadas que ele passou entre nós - para não dizer no seu conjunto.

A concepção de Willems da assimilação e dos processos a ela relacionados somente foi reforçada por seu contato com as ideias a ela ligadas vindas da sociologia norte-americana da época - e especialmente da Escola de Chicago - mas sem dúvida já vinha de antes. Em Berlim, no final da década de 1920, Willems foi aluno de Richard Thurnwald, que então representava uma linha de pesquisa que remontava a Philipp Wilhelm Adolf Bastian (1826-1905) na Alemanha, no século XIX. ${ }^{1}$

No $\S 9$ de seu texto, (à pág. 56 do original), Willems menciona existirem "princípios das possibilidades limitadas", sobre os quais o leitor não é esclarecido. Creio haver nisso uma influência das leituras dos textos de Thurnwald, pelos quais Willems manteve um longo interesse. O "princípio das possibilidades limitadas" foi proposto num artigo de 1913 por Alexander A. Goldenweiser, da Columbia University, no contexto de uma ampla discussão vinda do século XIX, envolvendo difusionistas e evolucionistas, sobretudo entre etnólogos alemães e continuada entre os norte-americanos por pelo menos duas décadas - o que permitiu redefinições, recontextualizações e revisões várias, entre tradições intelectuais e autores diversos (por exemplo, ainda em 1945, Ralph Linton considerava o conceito um critério crucial para a abordagem comparativa).

Richard Christian Thurnwald (1869-1954) doutorou-se em Direito na Áustria e foi para Berlim em 1900, onde se interessou pela etnologia e fez duas longas viagens à Nova Guiné Alemã e depois à África Oriental; só iniciou sua carreira universitária em 1919 em Halle e passou em 1923 à Universidade de Berlim, onde lecionou etnologia e sociologia, então em seus inícios, e se voltou para os problemas do colonialismo. Foi professor convidado em Yale, os Estados Unidos, em 1931-32 e em 1935-36, mas não conseguindo um posto em alguma universidade americana, retornou em 1936 à Alemanha, então sob domínio nazista, e passou a trabalhar para o Bureau Colonial do Reich em 1939; em 1946, aos 77 anos, tornou-se professor titular e colaborou na organização da Universidade Livre de Berlim-Oeste. Seus trabalhos incluem dezenas de artigos e os livros A Sociedade Humana em seus Fundamentos Etnosociológicos (1931-35, em 5 vols.), A Economia em Comunidades Primitivas (1932), Brancos e Negros na África Oriental (1935) e Estruturae Significado do Conhecimento Popular (1948) - dos quais apenas as 130 primeiras

1 Veja-se Viertler, Renate Brigitte. Os Fundamentos da Teoria Antropológica Alemã: Etnografia e Antropologia em Países de Língua Alemã: 170o-1950. Annablume: São Paulo, 2017. 
páginas do $5^{\mathrm{O}}$ volume do primeiro livro foram traduzidas por Emilio Willems entre 1941 e 1946 e publicadas em sequência no periódico Sociologia, então por ele editado em São Paulo.

No número de abril de 1937 da American Sociological Review, Thurnwald (1937) ${ }^{2}$ faz um breve levantamento dos diversos usos do conceito das "possibilidades limitadas" na análise dos "mecanismos da cultura" ("as possibilidades humanas oferecem apenas uma combinação restrita de situações, que podem recorrer em várias épocas independente de processo acumulativo" [p. 195]). As classifica, então, em três casos, em que são determinadas por condições biológicas, pela vida social e as determinadas pela psicologia humana, mais adiante indicando ainda um quarto fator, o geográfico; indica a necessidade e o potencial de análises contextuais de "situações elementares" e sugere ainda certo número de conceitos correlacionados, numa exposição com um acento funcionalista. Não seria por acaso que o "princípio das possibilidades limitadas" viria a estar presente tanto na ampla caracterização por Bronislaw Malinowski da "Cultura" no volume de 1931 da Encyclopedia of Social Sciences como também no criativo tratamento metodológico em A Lógica da Análise Funcional produzido por Carl G. Hempel em 1959.

Willems possivelmente viu na assimilação dos judeus uma dessas situações elementares, em que um elenco de possibilidades limitadas poderia ser identificado - e com ele se poderia assinalar um instrumento forte para a refutação do pressuposto biológico da impossibilidade da assimilação desse grupo social.

2 Thurnwald, R. The spell of limited possibilities: A contribution to an analysis of the mechanism of culture. American Sociological Review. V. 2, N. 2, 1937, p. 195-203.

Recebido: 11/10/2019 | Aprovado: 30/03/2020 